Original Research Paper

\title{
Field Data Based Method for Predicting Long-Term Settlements
}

\author{
${ }^{1}$ Jianping Jiang, ${ }^{2}$ Qingsheng Chen and ${ }^{3}$ Sanjay Nimbalkar \\ ${ }^{1}$ College of Ocean Science and Engineering, Shanghai Maritime University, Shanghai, 201306, China \\ ${ }^{2}$ Department of Civil and Environmental Engineering, National University of Singapore, 119077, Singapore \\ ${ }^{3}$ Centre for Geomechanics and Railway Engineering, Faculty of Engineering and Information Sciences, \\ University of Wollongong, Wollongong City, NSW 2522, Australia
}

Article history

Received: 10-11-2015

Revised: 08-01-2016

Accepted: 25-01-2016

Corresponding Author:

Qingsheng Chen

Department of Civil and

Environmental Engineering,

National University of Singapore,

119077, Singapore

Email: chqsh2006@163.com

\begin{abstract}
The estimation of the long-term foundation settlement in soft soil is very complex, which is attributed to a number of uncertainties associated with various factors, such as: (i) The compressibility parameters obtained in the laboratory from samples of relatively small size that are more homogeneous compared to heterogeneous field sediments in which various soil types may be interlayered at random and may occur without exhibiting any real stratification; (ii) limitations and unrealistic assumptions prevailing in the conventional consolidation analysis. These have often resulted in the large discrepancy between actual in-situ settlements and the predictions from the conventional consolidation models (e.g., Terzaghi's model). In this study, a field data based method inspired from an observational approach is proposed and validated against a number of high quality long-term field settlement data. Moreover, the corresponding geological soil properties obtained from field and laboratory tests have been presented, with the aim of providing useful practical references for other projects with similar geological profile. Furthermore, the proposed model is compared with existing prediction models. The results show that the newly proposed model can provide more reliable and accurate prediction of foundation settlements compared with other methods established in practice.
\end{abstract}

Keywords: Field Data Based Model, Long-Term Settlement Prediction, Conventional Consolidation Analysis, Complex Soil Formation

\section{Introduction}

The surface of the Aerodrome and the groundsills suffer from large settlements that occur over an extended period of time, when located on soft soils. As a result, predicting the long-term settlement on such soft soil has become a key element of safe design and long-term management of these engineering structures (Guo et al., 2009). The ultimate primary consolidation settlement is obtained using most conventional Terzaghi's conventional linear onedimensional model, in which, the differential equation is solved on the assumption that the coefficient of consolidation remains constant. But in reality, this equation is non-linear because compressibility, permeability and coefficient of consolidation changes with settlement (Huat, 1996). Although many improvements have been proposed by various authors taking into account some of these aspects (Brand and Brenner, 1981), the discrepancy between predicted values and actual in-situ settlements is still often evident, especially for heterogeneous soil deposits. This discrepancy is probably attributed to the fact that the compressibility parameters are usually obtained from conventional laboratory testing using relatively small sized and homogenous soil samples those are not representative of heterogeneous field sediments containing various soil types interlayered at random (Al-Shamrani, 2005). Moreover, consolidation settlement is a three-dimensional problem, especially 
for stratified soil deposits. The limitations of conventional one-dimensional consolidation analysis have been reported elsewhere (Duncan, 1993). In view of this, determination of more practical approach based on field measurements is both timely and imperative.

Field measurement data is a direct representation of the soil formation and in-situ stress conditions and provides much useful quantitative assessment of the foundation settlement. Many uncertainties (e.g., the variability of soil, magnitude and distribution of stresses) can be overcome by extrapolating $f$ om measured settlement data (Aboshi and Inouce, 1986). In past decades, a few field-based observational methods have been developed in order to predict future settlement behavior, such as the Hyperbolic (Tan, 1971; 1993; 1994; Chin, 1975; Ameranima, 2004; Al-Shamrani, 2005), Logistic (Yen and Scanlon, 1975; Hwang and Moh, 2006; $\mathrm{Xu}$ and $\mathrm{Li}$, 2007), Gompertz ( $\mathrm{Yu}$ and Liu, 2005; $\mathrm{Wu}$ and $\mathrm{Hu}$, 2006) and Asaoka (1978) methods. These methods have shown promising results for predicting behavior of complex soil formations once the sufficient field data is recorded. In view of this, new methods of analysis have become increasingly important to accurately estimate foundation settlement, given the availability of sufficient data.

In this study, an attempt is made to improve the capability of predicting the settlement, by proposed Gompertz-Logistic mathematical model combining the advantages of Gompertz Model and Logistic Model. This new model is then validated against a number of high quality long-term field settlement data collected from the observation points for three aerodrome groundsill sites (Fig. 1). In addition, the geological soil profile obtained from borehole data as well as the geotechnical characteristics of soils located at aerodrome groundsill site obtained from laboratory tests and field tests also described, with the aim of providing useful practical references for the settlement prediction for other projects with similar geological profile. Furthermore, the proposed model is compared with existing prediction models (i.e., Logarithmic method; Power method; Hyperbolic method; Compertz method and Logistic method). The results show that the newly proposed model can be more reliable and accurate in the prediction of foundation settlement compared with the existing prediction methods.

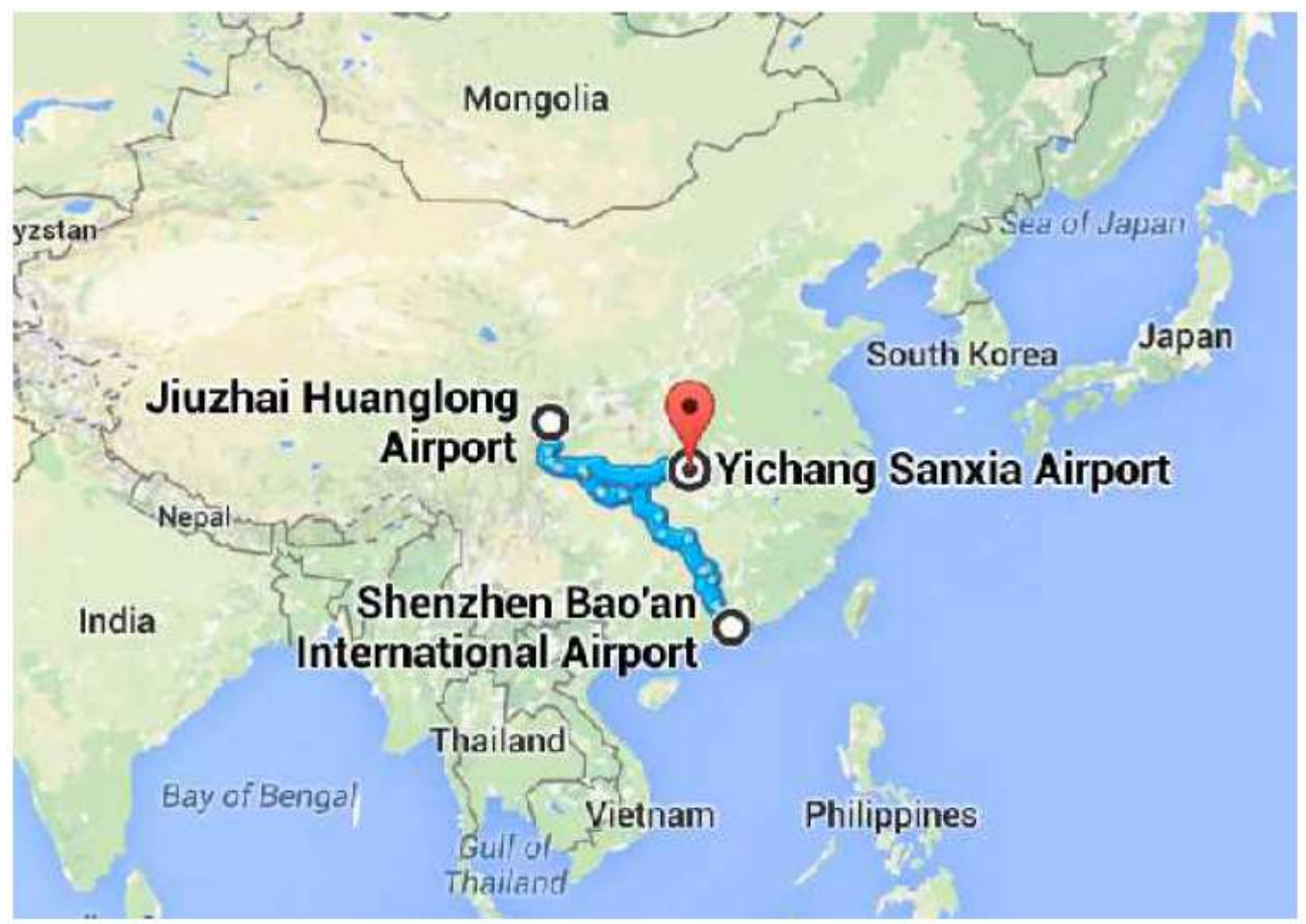

Fig. 1. Locations of the studied Airport in China 


\section{Mathematical Models}

\section{Logarithmic Model}

Yen and Scanlon (1975) determined the settlement rate for three landfills of $30 \mathrm{~m}$ in height, with the data recorded over a period of 9 years. The settlement rate was determined and approximated using the following logarithmic relationship:

$$
\frac{d s}{d t}=u^{\prime}-v^{\prime} \log t
$$

where, $d s / d t$ is rate of settlement, $u^{\prime}$ and $v^{\prime}$ are two empirical constants. They reported that the settlement rate in general showed increase with the depth of the fill. When $t$ becomes large, logarithmic model indicates that $d s / d t$ will be negative. It implies that a landfill will undergo expansion, which is physically impossible. Thus, in practice, $t$ should be limited to when $d s / d t=0$. The logarithmic function does not allow a maximum time to be defined such that the final settlement will be determined when the settlement rate approaches zero.

\section{Power Model}

The settlement rate can be related with time using power function (Edil et al., 1990):

$$
\frac{d s}{d t}=\frac{p^{\prime}}{t^{q^{\prime}}}
$$

where, $p^{\prime}$ and $q^{\prime}$ are two empirical constants. In this model, $p^{\prime}$ can also be defined as the settlement rate at unit time. Equation 1 and 2 can be integrated with respect to time to obtain settlement as (Ling et al., 1998):

$$
\begin{aligned}
& S=\left[u^{\prime}-v^{\prime}(\log t-1)\right] t \\
& S=\frac{p^{\prime}}{1-q^{\prime}} t^{1-q^{\prime}}
\end{aligned}
$$

As the settlement rate approaches zero (i.e., $d s / d t=$ 0 ), final settlements can be determined using Equation 3. The settlement can also be expressed using $\log t$ and power functions as (Ling et al., 1998):

$$
\begin{aligned}
& S=u+v \log t \\
& S=p t^{q}
\end{aligned}
$$

where, $u, v, p$ and $q$ are empirical constants. From Equation 4 and 6, it appears that $q=1-q^{\prime}$ and $p=p^{\prime} / q$.

\section{Hyperbolic Model}

In normal cases, foundation settlement shows rapid increase initially, followed by decreased rate of increase as time passes ultimately reaching the limit eventually (Hwang and Moh, 2006). Based on the experimental observations, Tan (1971) have proposed the following hyperbolic relationship to capture time dependent phenomenon of secondary compression:

$$
s=\frac{t}{\alpha+\beta t}
$$

where, $s$ is total settlement at any time, $t$, after the excess pore water pressure has dissipated; $\alpha$ and $\beta$ are two empirical constants to be established by curve fitting. Rearranging terms, Equation 1 can be rewritten as:

$\frac{t}{s}=\alpha+\beta t$

Equation 8 is the equation of a straight line (i.e., the plot of $t / s$ against $t$ ), where $\alpha$ and $\beta$ are the intercept and the slope of the line, respectively. These two constants can easily be obtained by regression analysis once sufficient data is available. Taking the limits of Equation 8 as $t$ approaches infinity, the total settlement is given by $1 / \beta$, which is the reciprocal of the slope of the straight line. The Hyperbolic method has become one of the most convenient and commonly used methods for predicting foundation settlements based on available field data (Tan, 1971; 1993; 1994; Ling et al., 1998; Ameranima, 2004; Al-Shamrani, 2005).

In this study, in order to extend the capability of prediction of Hyperbolic Model, Equation 7 is presented in following form:

$$
s=s_{0}+\frac{\alpha\left(t-t_{0}\right)}{1+\beta\left(t-t_{0}\right)}
$$

where, $s_{0}$ is the settlement at the time, $t_{0}$. Once the excess pore water pressure is dissipated, the total settlement can be determined as:

$s=s_{0}+\alpha / \beta$

\section{Logistic Model}

The general form of Logistic Model in the time series is expressed as:

$$
s=\frac{m}{1+n e^{-k t}}
$$


where, $s$ is the upper bound of $m, n$ describes the location of the curve and $k$ controls the shape of the curve. To estimate the parameters for $n$ and $k$, the equation of logistic model is transformed into linear natural logarithmic form. The linear model is expressed as:

$\ln (m /(s-m))=-\ln (n)+k t$

where, parameters $n$ and $k$ are then estimated using a simple linear regression. It is observed that the foundation settlement during loading can usually be divided into the occurrence phase, the development phase, the mature phase and the ultimate phase and the settlement-time curve bears ' $S$ ' shape. The Logistic Model can fit the whole process of foundation settlement well by choosing reasonable parameters (Mei et al., 2005; Li et al., 2011).

\section{Gompertz Model}

The Gompertz model was originally derived by Gompertz (1985) to describe the law of human mortality. More recently, it has also been used to predict biological and economic growth (Winsor, 1932; Batschelet, 1977). This shows that Gompertz Model can be used as a reliable and effective prediction tool.

The model exhibits ' $S$ ' type distribution curve, which is similar to the foundation settlement versus time curve. Also, the curve does not pass through the origin and it can appropriately represent the immediate settlement when the soil is under the action of load. Based on these important features, this model has been widely used in the past by many researchers for the prediction of foundation settlement ( $\mathrm{Yu}$ and Liu, 2005; Zeng and Kong, 2006).

The general form of Gompertz Model in the time series is expressed as:

$$
S=a e^{-e^{-b(t-c)}}
$$

where, $s$ is the predicted value of settlement at any time, t. $a, b$ and $c$ are constants, the parameter ' $a$ ' can also represent total settlement.

\section{Combined Gompertz-Logistic Model}

As discussed in the previous section, each prediction model has its own unique features. Bates and Granger (1969) proposed a method entitled 'Combined forecasting' in order to derive advantage of the available data as much as possible. Thus, accuracy of prediction can be improved by combining different forecasting methods discussed earlier thus enabling more systematic and comprehensive assessment.

In this study, a Combined Gompertz-Logistic Mathematical Model is proposed by taking the advantage of Gompertz Model and Logistic Model. The general form of the newly proposed model in time series is presented as:

$$
s=\frac{p_{1}}{1+p_{2} e^{\left(-p_{3} t\right)}}+p_{4} e^{-p_{5} e^{\left(-p_{6}\right)}}
$$

where, $s$ is the predicted value of settlement at any time, t. $p_{1}, p_{2}, p_{3}, p_{4}, p_{5}, p_{6}$ are the constants, the total settlement can be the value of the sum of $p_{1}$ and $p_{4}$. Due to the complexity of topography and the geotechnical conditions, many uncertainties for obtaining the soil parameters exists and it is a good option to apply the observational methods based on the field settlement measurement data to predict future settlement in the site of the airport, comparing with conventional analysis of consolidation settlement.

\section{Case Study}

The application of the proposed combined Gompertz-Logistic model is illustrated employing a number of high quality long-term field settlement data. The measurements reported for three aerodrome groundsill sites are used because of availability of relatively long-term settlement data: Shenzhen Bao'an International Airport, Guangdong, China (Wang et al., 2006); Three Gorges Airport, Hubei, China (Ren et al., 1998); Jiuzhai Huanglong Airport, Sichuan, China (Liu et al., 2005). The geological profile obtained from borehole data and the geotechnical characteristics of soils obtained from laboratory as well as field measurements at each aerodrome groundsill site are also presented, with the aim of providing useful practical reference for other projects with similar geological profile. Based on the comprehensive settlement data, the capability of the proposed model over other prediction models (i.e., Logarithmic method, Power method, Hyperbolic method; Compertz method and Logistic method) is assessed.

\section{Case I: Shenzhen Bao'an International Airport}

Shenzhen Bao'an International Airport is one of the three largest airport hubs serving southern China. The airport comprises of $3,400 \mathrm{~m}$ long and $45 \mathrm{~m}$ wide runway and a terminal building with $15,200 \mathrm{sq} \mathrm{m}$ area encompassing 24 jet ways. The airport is located in the eastern side of the estuary of Pearl River.

The original topography of the airport site was coastal plain and beach. According to the site investigation data (Wang et al., 2006), the geological profile and the geotechnical parameters of soils at the airport site obtained from laboratory as well as field tests are presented Fig. 2a and Table 1, respectively. The soil profile revealed the presence of soft soil with high water 
content, high compressibility and low shear strength which was mainly distributed within $6.4 \mathrm{~m}$ thick upper layer. In this project, the ground improvement was undertaken using surcharge as well as application of vertical sand drains spaced at $1 \mathrm{~m}$ and arranged in triangular pattern. The surcharge pressure of $140 \mathrm{kPa}$ was gradually applied and the $12 \mathrm{~m}$ long vertical drains were used accordingly. After ground improvement, the soil properties of muddy silt were significantly improved (Table 1).

Table 1. Soil parameters before and after ground improvement at Shenzhen Bao'an International Airport

\begin{tabular}{|c|c|c|c|c|}
\hline$\underline{\text { Parameters }}$ & Muddy silt & $\begin{array}{l}\text { Muddy silt after } \\
\text { ground improvement }\end{array}$ & Clayey loam & Silty clay \\
\hline Water content, $w(\%)$ & 81.50 & 58.30 & 19.70 & 23.20 \\
\hline Unit weight, $\gamma\left(\mathrm{kN} / \mathrm{m}^{3}\right)$ & 15.30 & 16.50 & 20.20 & 19.00 \\
\hline Void ratio, $e$ & 2.21 & 1.48 & 0.59 & 0.78 \\
\hline Liquid index, $\mathrm{I}_{\mathrm{L}}(\%)$ & 2.01 & 0.98 & $<0.00$ & $<0.00$ \\
\hline Compression index, $\mathrm{a}_{1-2}\left(\mathrm{MPa}^{-1}\right)$ & 2.03 & 0.94 & 0.25 & 0.35 \\
\hline Cohesion, $c(\mathrm{kPa})$ & 3.50 & 14.70 & 28.00 & 19.00 \\
\hline Friction angle, $\varphi(\mathrm{kPa})$ & 0.00 & 4.30 & 27.20 & 32.30 \\
\hline
\end{tabular}

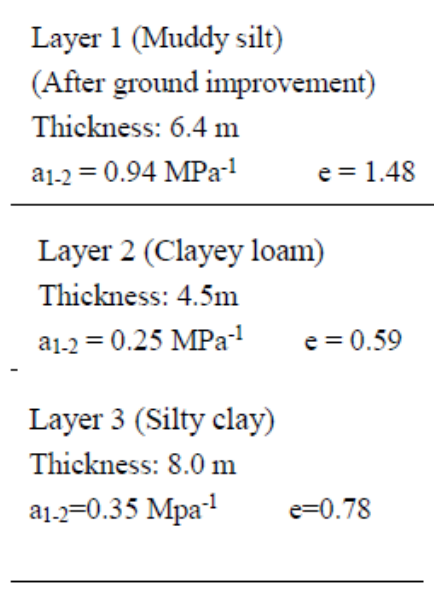

(a)

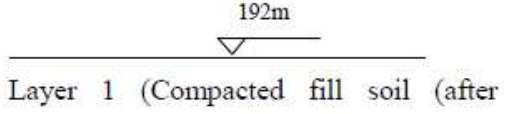

improvement))

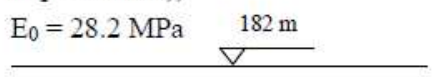

Layer 2 (Clayey gravel)

$\mathrm{E}_{0}=22.64 \mathrm{MPa}$

$\mathrm{e}=0.83$

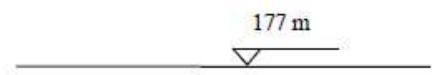

Layer 3 (Pebbles)

\begin{tabular}{l}
\hline Layer 1(Silt) \\
Thickness: $5.5 \mathrm{~m}$ \\
$\mathrm{E}_{0}=8.0 \mathrm{MPa}$ \\
\hline Layer 2 (Silty clay) \\
Thickness: $7.2 \mathrm{~m}$ \\
$\mathrm{E}_{0}=5.2 \mathrm{MPa}$ \\
\hline Layer 3 (Silty clay) \\
Thickness: $4.8 \mathrm{~m}$ \\
$\mathrm{E}_{0}=9.0 \mathrm{MPa}$ \\
\hline Layer 4 (Pebbly gravel) \\
Thickness: $3.0 \mathrm{~m}$ \\
$\mathrm{E}_{0}=5.2 \mathrm{MPa}$ \\
Layer 5 (Silty clay) \\
Thickness: over $7.4 \mathrm{~m}$ \\
$\mathrm{E}_{0}=9.0 \mathrm{MPa}$ \\
\hline
\end{tabular}

(b)

(c)

Fig. 2. Soil profile of the ground for studied cases (a) Soil profile after ground improvement: Case I (b) Soil profile after ground improvement: Case II (c) Soil profile: Case III 


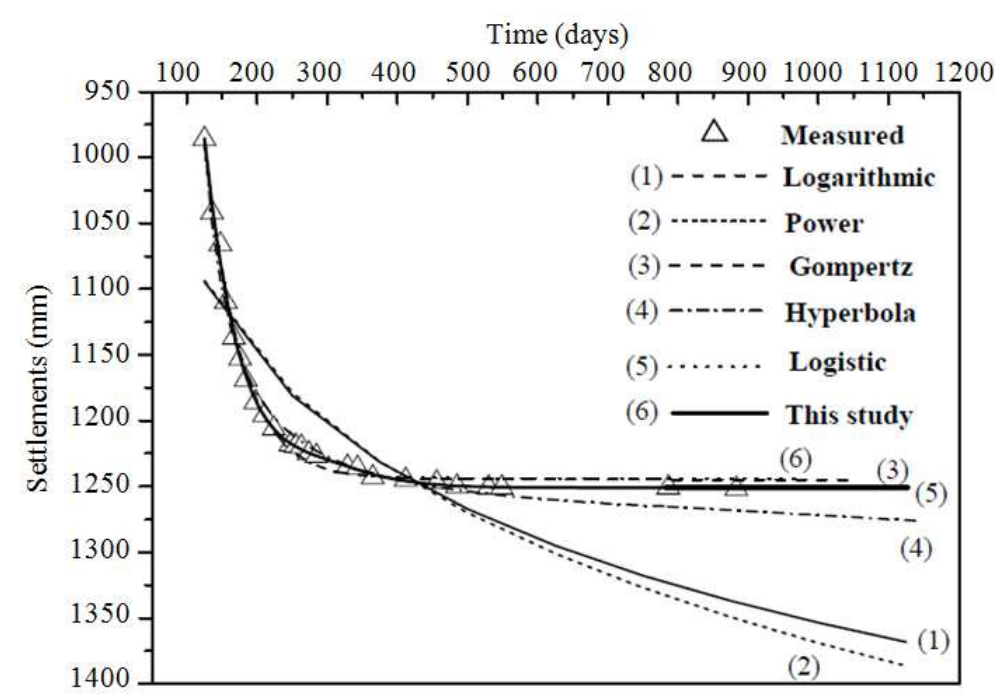

Fig. 3. Settlement estimations for observed point by the proposed model and the existing models for Shenzhen Bao'an International Airport

Figure 3 shows the comparison of settlements estimated by the proposed model and the existing models for Shenzhen Bao'an International Airport. Table 1 summarizes the best-fit parameters for each model, i.e., Logarithmic, Power, Hyperbolic, Logistic, Gompertz and proposed Gompertz-Logistic functions. Note that $R$ is the coefficient of correlation. As shown in Fig. 3, all the models show good agreement with measured data for the short-term settlement before 400 days. However, the discrepancy between predicted values by the existing methods (i.e., Logarithmic Method, Power Method, Gompertz Method, Hyperbolic Method and Logistic Method) and field data is much evident after 400 days. Logarithmic method and Power method show poor predictions with coefficient of regression around 0.70 , which is quite unacceptable. The predicted settlement by the Gompertz Model is in close agreement with the settlement predicted by Logistic method. The Logistic method predicts values somewhat smaller than the measured data, while the use of the Hyperbolic Model gives larger ultimate settlement than the measured data while the predicted settlement shows continuous increase with the time. This implies the inability of above both models in the accurate prediction of both short-term and long-term settlement of the airport foundation. On the contrary, the predicted settlement by the proposed model is in good agreement with the measured data. Currently, it is the only model that can produce estimation for both long-term settlement and short-term settlement consistently and reliably.

\section{Case II: Three Gorges Airport}

The Three Gorges Airport, which serves the world's largest dam project with regular air flights, is located in Yichang City, Hubei Province, China, 26 $\mathrm{km}$ away from the city center and $55 \mathrm{~km}$ from the Three Gorges Dam site. The airport, with runway of $2,600 \mathrm{~m}$ in length and $45 \mathrm{~m}$ in width and a terminal building of $15,000 \mathrm{sq} \mathrm{m}$, is capable of handling 1.4 million passengers annually. Soil parameters before and after ground improvement are listed in Table 2.

The region of the airport belongs to warm and humid subtropical climate zone, where the topography is uneven, the ditch and terraces are widely distributed. Based on the geotechnical investigation data, the soil deposits in the area mainly consist of Quaternary clay and pebble. The groundwater level is low and no active fault was found. The ground improvement was carried out by compaction method using the vibratory roller with the weights varying from 400 to $600 \mathrm{kN}$, to meet design criteria stipulated for the airport runway project viz. (i) the ultimate settlement of the ground in the airport should be less than $8 \mathrm{~cm}$, (ii) the values of differential settlement were not allowed to be larger than $1.5 \%$ and (iii) the compression rebound modulus should be larger than $25 \mathrm{MPa}$. Due to different requirements for the degree of compaction, the ground in the airport was divided into three observational areas for settlement measurements (i.e., Observational Area I, II and III, respectively). In this study, only the measured settlements for one observed point on the axis of the runway of the airport in Observational Area I was analysed (i.e., observed point of No.P94/H53+15 in the literature (Ren et al., 1998). For the ground at Observational Area I, the fill in the upper layer, which mainly consisted of clay with high liquid limit, was compacted to $98 \%$ relative compaction using the standard proctor test. The soil profile and soil parameters at the observed point before and after ground improvement are shown in Fig. $2 \mathrm{~b}$ and Table 3, respectively. 
Table 2. Soil parameters before and after ground improvement at three Georges airport

\begin{tabular}{|c|c|c|c|c|}
\hline Parameters & $\begin{array}{l}\text { Fill soil before } \\
\text { compaction }\end{array}$ & Clay & $\begin{array}{l}\text { Clay } \\
\text { with gravel }\end{array}$ & $\begin{array}{l}\text { Backfill soil } \\
\text { after compaction }\end{array}$ \\
\hline Water content, $w(\%)$ & 23.09 & 25.45 & 27.75 & 17.000 \\
\hline Unit weight, $\gamma\left(\mathrm{kN} / \mathrm{m}^{3}\right)$ & 19.48 & 19.30 & 18.67 & 20.360 \\
\hline Void ratio, $e$ & 0.73 & 0.78 & 0.83 & 0.525 \\
\hline Saturation degree, $S(\%)$ & 87.37 & 91.80 & 91.70 & 83.300 \\
\hline Specific gravity, $G$ & 2.75 & 2.75 & 2.75 & 2.750 \\
\hline Liquidity limit, $w_{L}(\%)$ & 37.56 & 37.19 & 36.94 & 39.200 \\
\hline Plasticity limit, $w_{p}(\%)$ & 22.37 & 24.35 & 26.80 & 25.150 \\
\hline Deformation modulus, $E_{0}(\mathrm{MPa})$ & 22.00 & 20.60 & 22.64 & 28.200 \\
\hline
\end{tabular}

Table 3. Physical and mechanical parameters for weak soil at Jiuzhai Huanglong Airport

\begin{tabular}{|c|c|c|c|c|c|}
\hline Parameters & Silt & Silty clay & Silty clay & Pebbly gravel & Silty clay \\
\hline Water content, $w(\%)$ & 21.90 & 24.50 & 25.20 & 22.50 & 22.80 \\
\hline Unit weight, $\gamma\left(\mathrm{kN} / \mathrm{m}^{3}\right)$ & 18.50 & 19.00 & 19.50 & 19.00 & 19.50 \\
\hline Void ratio, $e$ & 0.62 & 0.62 & 0.70 & 0.58 & 0.64 \\
\hline Liquidity limit, $w_{L}(\%)$ & 0.51 & 0.58 & 0.48 & 0.65 & 0.45 \\
\hline Deformation modulus, $E_{0}(\mathrm{MPa})$ & 8.00 & 5.20 & 9.00 & 5.20 & 9.00 \\
\hline
\end{tabular}

Figure 4 shows the predictions using the proposed model and the existing models for estimation of settlement in Observational Area I. Table 4 summarizes the best-fit parameters for each model, i.e., Logarithmic, Power, Hyperbolic, Logistic, Gompertz and proposed Gompertz-Logistic functions. As shown in Fig. 4, an acceptable agreement between the measured data and the predictions of various methods discussed in this study can be achieved for the initial stage of settlement, i.e., before 40 days. The application of Power method results into underprediction of settlements before 80 days while resulting into large deviations for the following period of measurements. The Hyperbola method over predicts settlements by a substantial amount for the period above 100 days. Most of existing methods fail to provide satisfactory predictions of long-term settlement of over 100 days, especially the predictions by Logarithmic, Power and Hyperbola functions (Fig. 4). Although predictions by Gompertz Model and Logistic Model provide satisfactory match with the field data for a short period of measurements, the proposed method gives a good agreement between the predictions and the measured data during the entire period. The non-linear variation of settlement against time duration is adequately captured by the proposed model.

\section{Case III: Jiuzhai Huanglong Airport}

Jiuzhaigou Huanglong Airport, with an altitude of 3,400 meters, is the third highest airport in China, which has a $3200 \mathrm{~m}$ long and $60 \mathrm{~m}$ wide runway. The airport is located on the boundary between eastern Tibetan Plateau and the Sichuan Basin, i.e., northern part of Eshan mountain on the Northwest Plateau in Sichuan. The topography and geotechnical conditions in the airport area are very complex, which belongs to high altitude zone $(3430 \mathrm{~m})$, high earthquake intensity zone (common earthquake intensity of 8.1 degrees) and high fill zone (the vertical height of Yuan Shanzi ditch in the site of the airport was over $102 \mathrm{~m}$ and the height of fill from the bottom of the ditch to the pavement surface was up to $140 \mathrm{~m}$ after completion of the fill in the ditch with the earthwork over 58 million $\mathrm{m}^{3}$ ).

According to the geological survey and geotechnical investigation data, the soft soil of Yuanshanzi group mainly consisted of yellow-gray silt, which belongs to the eolian loess with large pore structure, large compressibility and low mechanical strength due to long-term immersion in the underground water. The soft soil of Heshi group, mainly consisted of brown-yellow, gray and dark gray silty clay with gravels and silty clay. Similarly, due to this group of soil layer lies to low-lying terrain, the soil was immerged in underground water and exhibited weak soil properties with low strength and high compressibility. The soil profile and soil parameters are shown in Fig. 2c and Table 3, respectively.

Figure $5 \mathrm{a}$ and $\mathrm{b}$ show the predictions of settlements using the proposed model and the existing models at the observed point $\mathrm{C} 18$ and $\mathrm{C} 25$, respectively, compared with the measured data. Table 4 summarizes the best-fit parameters for each model, i.e., Logarithmic, Power, Hyperbolic, Logistic, Gompertz and proposed Gompertz-Logistic functions. An excellent agreement between the predictions of the proposed model and the field data is evident from Fig. $5 \mathrm{a}$ and $\mathrm{b}$. Most of other established methods yield quite scattered results. While Hyperbolic, Logistic, Gompertz methods show good agreement for some range of data, the proposed model provides 
predictions which compare well over the entire range of data measured during the period of this study. Most of other existing methods are found approximate and give a wide scatter of predicted values after 90 days at observation point $\mathrm{C} 18$ (Fig. 5a) and after 110 days at observation point C25 (Fig. 5b). On the contrary, the proposed model is able to capture the complex nonlinear trend in the long-term settlement of aerodrome groundsill, albeit with the need to employ more number of parameters.

Table 4. Best-Fit Parameters for mathematical models for settlement predictions Mathematical Model Parameters Best-fit values

\begin{tabular}{|c|c|c|c|c|c|}
\hline & & Case I & Case II & Case III (C18) & Case III (C25) \\
\hline \multirow[t]{3}{*}{ Logarithmic Model } & $\mathrm{u}$ & 493.51000 & -5.536000 & -29.99300 & -43.98500 \\
\hline & $\mathrm{v}$ & 124.50000 & 2.355000 & 16.99300 & 22.56800 \\
\hline & $\mathrm{R}$ & 0.70120 & 0.970200 & 0.93730 & 0.90550 \\
\hline \multirow[t]{3}{*}{ Power Model } & $\mathrm{p}$ & 649.19000 & 0.144500 & 0.30440 & 0.26570 \\
\hline & $\mathrm{q}$ & 0.10800 & 0.798500 & 1.09570 & 1.18160 \\
\hline & $\mathrm{R}$ & 0.67830 & 0.897900 & 0.87540 & 0.86970 \\
\hline \multirow{5}{*}{ Hyperbolic Model } & $\alpha$ & 0.13400 & 0.105000 & 0.87507 & 0.94400 \\
\hline & $\beta$ & 0.00338 & 0.013520 & 0.00885 & 0.00550 \\
\hline & $s_{0}$ & 986.00000 & 1.200000 & 1.03755 & 1.03755 \\
\hline & $t_{0}$ & 125.00000 & 16.000000 & 3.40534 & 3.40534 \\
\hline & $R$ & 0.98680 & 0.905400 & 0.91260 & 0.88570 \\
\hline \multirow[t]{4}{*}{ Logistic Model } & $m$ & 1243.77400 & 5.404500 & 53.16660 & 73.95900 \\
\hline & $n$ & 3.97000 & 8.138000 & 14.32100 & 11.85000 \\
\hline & $k$ & 0.02200 & 0.057110 & 0.05235 & 0.04345 \\
\hline & $R$ & 0.99620 & 0.976300 & 0.97680 & 0.97220 \\
\hline \multirow[t]{4}{*}{ Gompertz Model } & $a$ & 1244.47500 & 5.600000 & 55.40000 & 78.06700 \\
\hline & $b$ & 0.02060 & 0.039200 & 0.03338 & 0.02790 \\
\hline & $c$ & 53.39600 & 27.540000 & 39.28000 & 44.70000 \\
\hline & $R$ & 0.99670 & 0.954800 & 0.98020 & 0.94590 \\
\hline Combined Gompertz-Logistic & $p_{1}$ & 1230.46600 & 0.644084 & 40.93660 & 15.33378 \\
\hline \multirow{6}{*}{ Model } & $p_{2}$ & 6.06000 & $3.7 * 1070$ & 28.37000 & $1.3 * 109$ \\
\hline & $p_{3}$ & 0.02555 & 0.251620 & 0.08430 & 0.20217 \\
\hline & $p_{4}$ & 20.58000 & 4.760000 & 13.67000 & 58.70000 \\
\hline & $p_{5}$ & 450.20000 & 3.060000 & 229.70000 & 4.78000 \\
\hline & $p_{6}$ & 0.01796 & 0.047900 & 0.05969 & 0.04521 \\
\hline & $R$ & 0.99870 & 0.998820 & 0.99910 & 0.99870 \\
\hline
\end{tabular}

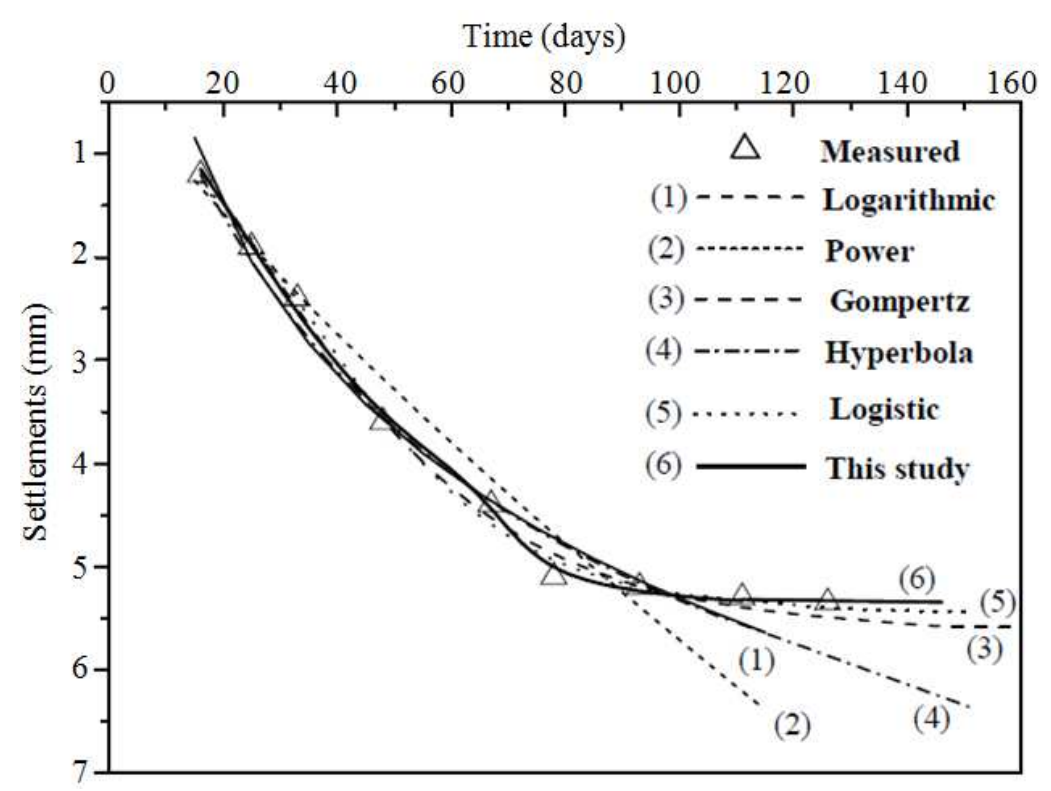

Fig. 4. Soil profile after ground improvement and settlement estimations for observed point by the proposed model and the existing models 


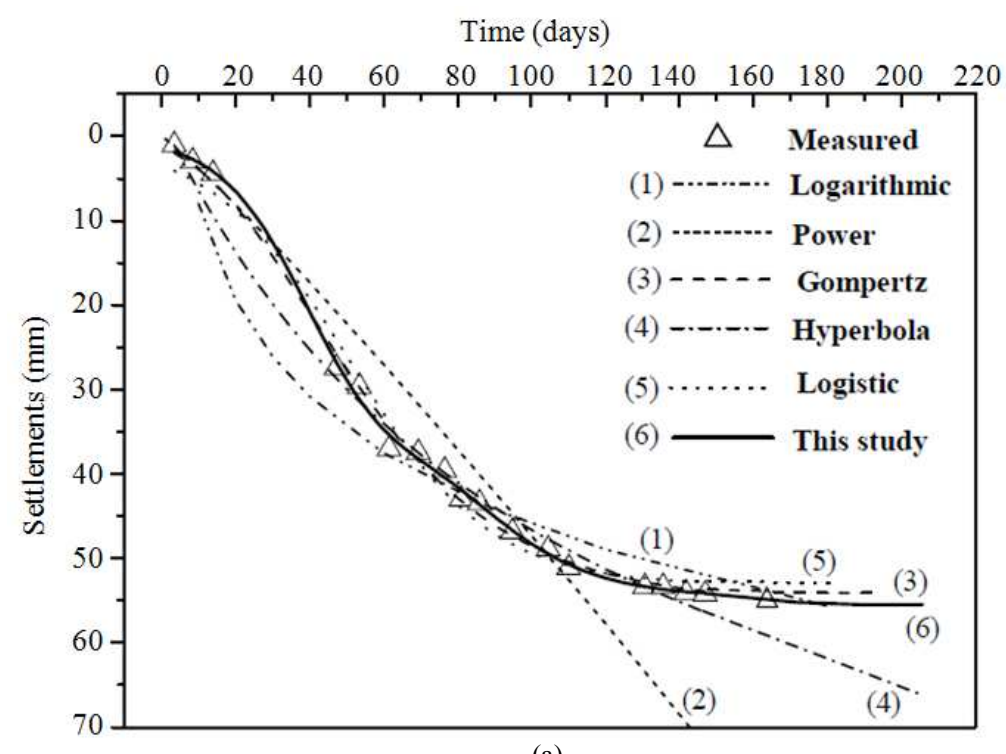

(a)

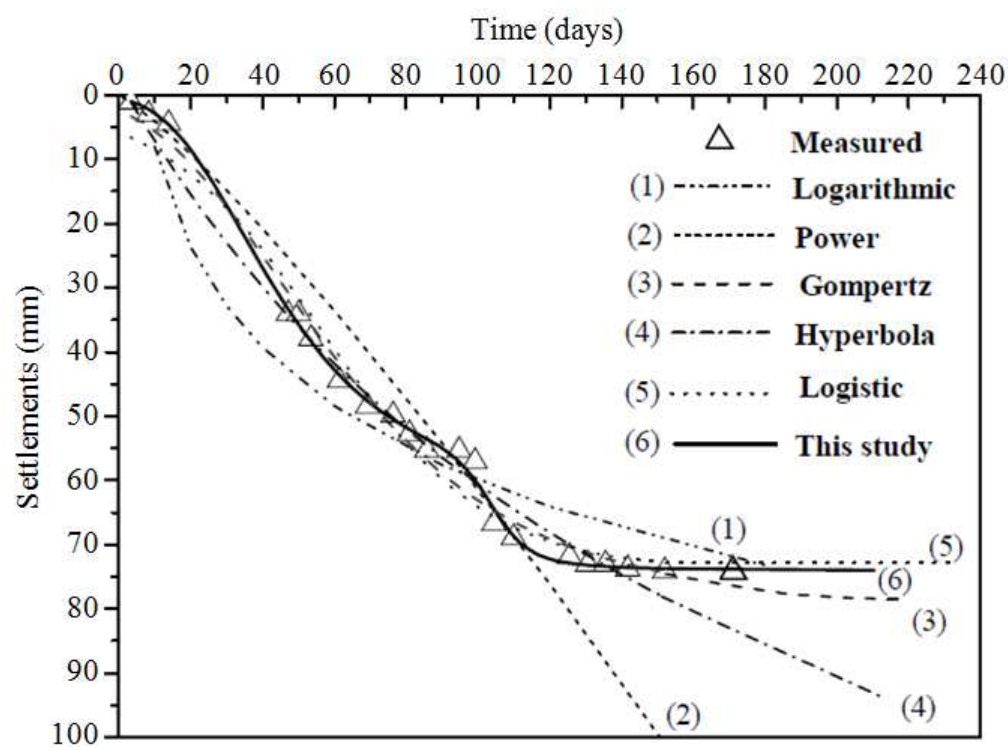

(b)

Fig. 5. Settlement Estimations for Jiuzhai Huanglong Airport by the proposed Model and the Existing Models at (a) observation point $\mathrm{C} 18$ and (b) observation point $\mathrm{C} 25$

\section{Conclusion}

In this study, the feasibility of predicting the settlement of soft ground by a newly proposed field based method is presented with sufficient validation. Three field based investigations related to the settlement of soft ground, along with the corresponding geological soil properties obtained from field and laboratory tests were presented and used for model development and verification. A new model based on an observational approach is proposed in the view of limitations of the existing model established in practice. The comparison is carried out between the model predicted and field measured values. This paper shows that the newly proposed model is able to predict the settlement of the complex soft ground with an acceptable degree of accuracy and has much better performance than the existing observational methods. Once the sufficient field data is available, the proposed model is featured as an accurate and fast tool without need to use any tables or charts, thereby overcoming the shortcomings of the conventional consolidation analysis due to various uncertainties for obtaining the necessary soil 
parameters. The main shortcoming of the proposed method is the lack of computational theory based on rigorous mathematics to help in its development. However, despite the foregoing limitations, this study highlights that the proposed field based observational approach has a number of significant benefits thus making it a simple, yet powerful and practical tool for settlement prediction of soft ground, especially with complex soil formations.

\section{Acknowledgement}

This research is funded by the National Natural Science Foundation of China (No: 41372319), Shanghai Municipal Education Commission Research Innovation Foundation (14YZ101), Shanghai Maritime University Innovation Team Foundation (A113010041004), Shanghai Maritime University Research Foundation (20120074) and Shanghai Municipal Education Commission Primary Discipline Doctoral Program Foundation.

\section{Author's Contributions}

All authors equally contributed in this work.

\section{Ethics}

This article is original and contains unpublished material. The corresponding author confirms that all of the other authors have read and approved the manuscript and no ethical issues involved.

\section{References}

Aboshi, H. and T. Inoue, 1986. Prediction of consolidation settlement of clay layers especially in case of soil stabilisation by vertical drains. Proceedings of the IEM-JSSMFE Symposium on Geotechnical Problems, (SGP' 86), Kuala Lumpur, pp: 31-40.

Al-Shamrani, M.A., 2005. Applying the hyperbolic method and $\mathrm{C}_{\alpha} / \mathrm{C}_{\mathrm{c}}$ concept for settlement prediction of complex organic-rich soil formations. Eng. Geol., 77: 17-34. DOI: 10.1016/j.enggeo.2004.07.004

Ameranima, A., 2004. Applicability of the rectangular hyperbolic method to settlement predictions of sabkha soils. Geotechn. Geol. Eng., 22: 563-587. DOI: 10.1023/B:GEGE.0000047046.73649.04

Asaoka, A., 1978. Observational procedure of settlement prediction. Soils Foundat., 18: 87-101. DOI: $10.3208 /$ sandf1972.18.4 87

Bates, J.N. and C.W.J. Granger, 1969. The combination of forecasts. J. Operat. Res., 20: 451-468.

DOI: $10.1057 /$ jors. 1969.103
Batschelet, E., 1977. Introduction to mathmatics for life scientists. Acta Biotheoretica, 26: 196-200.

Brand, E.W. and R.P. Breers, 1981. Soft Clay Engineering. 1st Edn., Elsevier Scientific Publishing Co., Amsterdam, ISBN-10: 0444417842, pp: 779.

Chin, F.K., 1975. The seepage theory of primary and secondary consolidation. Proceedings of the 4th Southeast Asian Conference on Soil Engineering, (CSE' 75), Kuala Lumpur, pp: 21-28.

Duncan, J.M., 1993. Limitations of conventional analysis of consolidation settlement. J. Geotechn. Eng., 119: 1333-1359.

DOI: 10.1061/(ASCE)0733-9410(1993)119:9(1333)

Edil, T.B., V.J. Ranguette and W.W. Wuellner, 1990. Settlement of municipal refuse, geotechnics of waste fills-theory and practice: ASTM STP 1070(pp. 225239): American Society for Testing and Materials, Philadelphia, $\mathrm{Pa}$.

Gompertz, B., 1825. On the nature of the function expressive of the law of human mortality and on a new mode of determining the value of life contingencies. Philosophical Trans. R Society London, 123: 513-585. DOI: 10.1098/rstl.1825.0026

Guo, J., J.J. Zheng and Y. Liu, 2009. Application of an immune algorithm to settlement prediction. J. Zhej. Univ. Sci. A, 10: 93-100.

DOI: $10.1631 /$ jzus.A0820289

Huat, B.B.K., 1996. Observational method of predicting settlements. Proceedings of the 12th Southeast Asian Geotechnical Conference, (AGC' 96), Kuala Lumpur, pp: 191-196.

Hwang, R.N. and Z.C. Moh, 2006. Prediction of longterm settlements induced by shield tunneling. J. GeoEng., 1: 63-70.

Ling, H.I., D. Leshchinsky, Y. Mohri and T. Kawabata, 1998. Estimation of municipal solid waste landfill settlement. J. Geotechn. Geoenviron. Eng., 124: 21-28. DOI: 10.1061/(ASCE)1090-0241(1998)124:1(21)

Liu, H., P.F. Li and Z.Y. Zhang, 2005. Prediction of the post-construction settlement of the high embankment of Jiuzhai-Huanglong Airport. Chinese J. Geotechn. Eng., 27: 0-93.

Li, Y.Q., H. Zhang and Y.R. Liu, 2011. Regression analysis of observed foundation settlement by modified logistic growth model. Adv. Mater. Res., 250-253: 2583-2587.

DOI: 10.4028/www.scientific.net/AMR.250-253.2583

Mei, G.X., J.M. Zai and Z.Z. Yin, 2005. Proof of settlement-time curve appearing " $S$ " shape with ramp load and its application based on stress-strain relationship. Rock Soil Mechan., 26: 21-24.

Ren, D.J., X.J. He and C.H. Yao, 1998. The settlement results analysis of Sanxia Airport No.1 area. Geotechn. Eng. Technique, 1: 55-59. 
Tan, S.B., 1971. An empirical method for estimating secondary and total settlement. Proceedings of the 4th Asian Regional Conference on Soil Mechanics and Foundation Engineering, (MFE' 71), Bangkok, pp: $147-151$

Tan, T.S., 1993. Ultimate settlement by hyperbolic plot for clays with vertical drains. J. Geotechn. Eng., 119: 950-956.

DOI: 10.1061/(ASCE)0733-9410(1993)119:5(950)

Tan, T.S., 1994. Hyperbolic method for evaluation of settlement of ground pretreated by drains and surcharge. Geotechn. Eng., 25: 75-89.

Wang, Z.L., J.Z. Huang and Y.C. Li, 2006. Study on application of Asaoka's method to settlement prediction. Rock Soil Mechan., 27: 2025-2029

Winsor, C., 1932. The Gompertx curve as a growth equation. Proc. Nat. Acad. Sci., 18: 1-8.
$\mathrm{Wu}$, Q.X. and $\mathrm{H} . \mathrm{Hu}, 2006$. Law analysis of soft soil settlement treated by vacuum preloading based on Gompertz growth curve. Chinese J. Rock Mechan. Eng., 25: 3600-3606.

$\mathrm{Xu}, \mathrm{H} . Z$. and X. Li, 2007. Time function of surface subsidence based on logistic growth model. Rock Soil Mechan., 26: 151-153.

Yen, B.C. and B. Scanlon, 1975. Sanitary landfill settlement rates. J. Geotechn. Eng. Div., 105: 475-487.

$\mathrm{Yu}, \mathrm{C}$. and S.Y. Liu, 2005. A study on prediction of embankment settlement with the gompertz model. Rock Soil Mechan., 26: 82-86.

Zeng, W. and X. Kong, 2006. The research on Gompertz model prediction on high fill embankment. Highways Automotive Applic., 115: 81-83. 